\title{
Malignant Orbit Neoplasm
}

National Cancer Institute

\section{Source}

National Cancer Institute. Malignant Orbit Neoplasm. NCI Thesaurus. Code C3562.

A primary or metastatic malignant neoplasm involving the orbit. 